\title{
Perioperative planning in the COVID-19 pandemic: Vascular issues
}

\author{
COVID-19 pandemisinde perioperatif planlama: Damar hastalıkları
}

\author{
Tankut Akay (1)
}

Department of Cardiovascular Surgery, Başkent University Medical Faculty, Ankara, Turkey

The severe acute respiratory syndromecoronavirus-2 (SARS-CoV-2; COVID-19) pandemic has changed not only the paradigm of maintenance of healthcare system for healthcare providers and governments, but also the whole world since December 2019, and there is a growing number of data accumulating from may centers across the globe..$^{[1,2]}$ Expert opinion reports estimate that the impact of COVID-19 seems to be evident in the following months; therefore, as cardiovascular surgeons, we must be very well prepared in this outbreak period. I have read with great interest the article entitled "Perioperative planning for cardiovascular operations in the COVID-19 pandemic" written by Mavioğlu et al. ${ }^{[3]}$ In my opinion, this article will be a helpful guide, particularly at this particular moment. ${ }^{[3]}$ As a proud member of this society, I would like to make humble contributions to this paper.

It has been established that age and underlying cardiovascular diseases such as hypertension, diabetes, and myocardial infarction are the most important risk factors for mortality from COVID-19 pneumonia. ${ }^{[4-6]}$ Malnutrition and superimposed bacterial infections may also worsen the prognosis and prolong the length of intensive care unit stay. In some cases, multiple organ dysfunction may develop and the most common organ damage is lung, followed by the heart, kidney, and liver. During this outbreak, many reports have been published, mainly focusing on minimizing contamination and protecting the healthcare providers. However, data are still scarce about the management of patients with diseases other than COVID-19 infection, urging us to obtain expert opinions.
In addition to many cardiovascular risk factors listed above which can affect COVID-19 patients, it is also of vital importance to consider a vulnerable group of patients, such as individuals waiting for cardiac transplantation or post-heart transplantation. In China, two heart transplant patients with typical symptoms of COVID-19 have been recently reported.$^{[7,8]}$ In addition, COVID-19-infected patients seem to be at an increased risk for venous thromboembolism (VTE). Although there are no published case series thus far, there are reports of abnormal coagulation parameters in hospitalized patients with severe COVID-19 disease..$^{[9,10]}$ In a multi-center, retrospective cohort study from China, elevated D-dimer levels $(>1 \mathrm{~g} / \mathrm{L})$ were found to be strongly associated with in-hospital mortality, even after multivariable adjustment (OR $18.4,95 \%$ CI 2.6-128.6, p=0.003). In another study comparing COVID-19 survivors to non-survivors, nonsurvivors had significantly higher D-dimer and fibrin degradation product levels and $71.4 \%$ of non-survivors met clinical criteria for disseminated intravascular coagulation during the course of their disease. ${ }^{[9]}$ The high incidence of VTE in critically ill patients of COVID-19, despite the universal use of guidelinerecommended VTE prophylaxis, was similar to sepsis, but markedly higher than published reports in critically ill patients without sepsis, indicating dysregulated hemostasis and coagulation in severe COVID-19. Vascular inflammation may also contribute to the hypercoagulable state and endothelial dysfunction in these patients. In the setting of critically ill COVID-19 patients having clinical deterioration as evidenced by hypoxia or hemodynamic instability, thromboembolic

Received: April 13,2020 Accepted: April 14, 2020 Published online: April 22, 2020

Correspondence: Tankut Akay, MD. Başkent Üniversitesi Tıp Fakültesi Kalp ve Damar Cerrahisi Anabilim Dalı, 06490 Bahçelievler, Ankara, Türkiye. Tel: +90 312 - 2036868 / 2560 e-mail: tankutakay@gmail.com 
Table 1. Recommendation about venous procedures and wound

\begin{tabular}{l|ll}
\hline & $\begin{array}{l}\text { Acute iliofemoral DVT with phlegmasia } \\
\text { Inferior vena cava filter placement } \\
\text { Massive symptomatic iliofemoral DVT in low risk patient } \\
\text { Procedures for ulcerations secondary to venous disease } \\
\text { Asymptomatic May-Thurner syndrome } \\
\text { Inferior vena cava filter removal }\end{array}$ & $\begin{array}{l}\text { Do not postpone } \\
\text { Postpone if possible }\end{array}$ \\
Varicose veins, GSV ablations & Postpone if possible \\
& $\begin{array}{l}\text { Amputations for infection/necrosis (TMA, BKA, AKA) } \\
\text { Lower extremity disease with non-salvageable limb (amputation) }\end{array}$ & Postpone \\
Deep debridement of surgical wound infection or necrosis & Postpone \\
Wounds requiring skin grafts & Postpone \\
Amputations for infection/necrosis (toes) & Do not postpone \\
\hline
\end{tabular}

DVT: Deep vein thrombosis; GSV: Greater saphenous vein; TMA: Transmetatarsal amputation; BKA: Below-knee amputation; AKA: Above-knee amputation.

disease should be considered. The optimal treatment for patients hospitalized with COVID-19-related illness is still unknown. There are recommendations for deep vein thrombosis (DVT) and VTE. One of the recommendations is given by the American College of Surgeons for all vascular procedures. ${ }^{[11]}$ In this short communication, only the recommendations for venous procedures and for inoperable patients with wound/gangrene/amputation are given in Table 1 . More effective VTE prevention strategies based on an individual assessment of bleeding risks have a vital importance for critically ill patients with COVID-19. ${ }^{[12]}$ Given the drug-drug interactions between some antiviral treatments and direct oral anticoagulants, lowmolecular- weight heparins, or unfractionated heparin with or without mechanical prophylaxis are likely to be preferred in all patients with COVID-19, if possible. All completely immobilizsed patients would benefit from intermittent pneumatic compression in addition to pharmacological thromboprophylaxis. Mechanical thromboprophylaxis should be used alone, if platelet count is less than 30,000 per microliter or in a bleeding patient.

Critically ill patients with COVID-19 suffer from both a high risk of thrombosis and bleeding. The Padua Prediction Score for Risk of VTE may be a helpful tool for this purpose. ${ }^{[13]}$ More effective VTE prevention strategies based on an individual assessment of bleeding risks have a vital importance for critically ill patients with COVID-19.
In conclusion, to the best of our current knowledge and understanding, we, as vascular surgeons, should immediately develop certain algorithms for preventing DVT and identify possible treatment approaches to follow during this outbreak.

\section{Declaration of conflicting interests}

The author declared no conflicts of interest with respect to the authorship and/or publication of this article.

\section{Funding}

The author received no financial support for the research and/or authorship of this article.

\section{REFERENCES}

1. Grech V. Unknown unknowns - COVID-19 and potential global mortality. Early Hum Dev 2020;144:105026.

2. Chen X, Liu Y, Gong Y, Guo X, Zuo M, Li J, et al. Perioperative Management of Patients Infected with the Novel Coronavirus: Recommendation from the Joint Task Force of the Chinese Society of Anesthesiology and the Chinese Association of Anesthesiologists. Anesthesiology 2020. [Epub ahead of print]

3. Mavioğlu HL, Ünal EU, Aşkın G, Küçüker ŞA, Özatik MA. Perioperative planning for cardiovascular operations in the COVID-19 pandemic. Turk Gogus Kalp Dama 2020;28:236-43.

4. Yang X, Yu Y, Xu J, Shu H, Xia J, Liu H, et al. Clinical course and outcomes of critically ill patients with SARSCoV-2 pneumonia in Wuhan, China: a single-centered, retrospective, observational study. Lancet Respir Med 2020. pii: S2213-2600(20)30079-5. 
5. Huang C, Wang Y, Li X, Ren L, Zhao J, Hu Y, et al. Clinical features of patients infected with 2019 novel coronavirus in Wuhan, China. Lancet 2020;395:497-506.

6. Wang D, Hu B, Hu C, Zhu F, Liu X, Zhang J, et al. Clinical Characteristics of 138 Hospitalized Patients With 2019 Novel Coronavirus-Infected Pneumonia in Wuhan, China. JAMA 2020. [Epub ahead of print]

7. Liu R, Ming X, Xu O et al. First Cases of COVID-19 in Heart Transplantation From China. J Heart Lung Transplant 2020 [In-press].

8. Aslam S, Mehra MR. COVID-19: Yet another coronavirus challenge in transplantation. J Heart Lung Transplant 2020. pii: S1053-2498(20)31468-6. [Epub ahead of print]

9. Tang N, Li D, Wang X, Sun Z. Abnormal coagulation parameters are associated with poor prognosis in patients with novel coronavirus pneumonia. J Thromb Haemost 2020;18:844-7.
10. Fan BE, Chong VCL, Chan SSW, Lim GH, Lim KGE, Tan GB, et al. Hematologic parameters in patients with COVID-19 infection. Am J Hematol 2020. [Epub ahead of print]

11. American College of Surgeons. COVID-19 Guidelines for Triage of Vascular Surgery Patients. Available at: https:// www.facs.org/-/media/files/covid19/guidance_for_triage_ of_nonemergent_surgical_procedures_vascular.ashx. 2020. [Accessed: March 27, 2020]

12. Günertem E, Akay T, Aliyev A, Beyazpınar S, Erdil N, Erer $\mathrm{D}$, et al. Treatment and prophylaxis strategies for deep vein thrombosis during COVID-19 outbreak. Turk J Vasc Surg 2020. [In Press]

13. Barbar S, Noventa F, Rossetto V, Ferrari A, Brandolin $\mathrm{B}$, Perlati $\mathrm{M}$, et al. A risk assessment model for the identification of hospitalized medical patients at risk for venous thromboembolism: the Padua Prediction Score. J Thromb Haemost 2010;8:2450-7. 